\section{Comments on "The North American Regional Climate Change Assessment Program: Overview of Phase I Results"}

provide useful information about climate change. In particular, the results from phase I of [the North American Regional Climate Change Assessment Program] NARCCAP will be used to establish uncertainty due to boundary conditions as well as final weighting of the models for the development of regional probabilities of climate change.

However, this conclusion overstates the significance of their findings in terms of its application to the multidecadal prediction of regional climate (i.e., "climate change"). The Mearns et al. study uses observational data (from a reanalysis) to drive the regional models. Using the classification we have introduced in Castro et al. (2005), Mearns et al. is a type 2 dynamic downscaling study.

As we wrote in Pielke and Wilby (2012, p. 52),

type 2 dynamic downscaling refers to regional weather (or climate) simulations ... in which the regional model's initial atmospheric conditions are forgotten ... but results still depend on the lateral boundary conditions from a global numerical weather prediction where initial observed atmospheric conditions are not yet forgotten or are from a global reanalysis.... Downscaling from reanalysis products (type 2 downscaling) defines the maximum forecast skill that is achievable with type 3 and type 4 downscaling.

In contrast

type 4 dynamic downscaling takes lateral boundary conditions from an Earth system model in which coupled interactions among the atmosphere, ocean, biosphere, and cryosphere are predicted.... Other than terrain, all other components of the climate system are calculated by the model except for human forcings, including greenhouse gas emissions scenarios, which are prescribed. Type 4 dynamic downscaling is widely used to provide policy makers with impacts from climate decades into the future. . . Type 4 downscaling has practical value but with the very important caveat that it should be used for model sensitivity experiments and not as predictions (Pielke 2002; Prudhomme et al. 2010). 
As discussed in Pielke and Wilby, type 1 downscaling is used for short-term, numerical weather prediction, while type 3 dynamic downscaling takes lateral boundary conditions from a global model prediction forced by specified realworld surface boundary conditions, such as seasonal weather predictions based on observed sea surface temperatures. Because real-world observational constraints diminish from type 1 to type 4 downscaling, uncertainty grows as more climate variables must be predicted by models, rather than obtained from observations.

One cannot, therefore, use type 2 downscaling to make claims, as Mearns et al. (2012) have, about the accuracy of type 4 downscaling. Type 2 downscaling provides a real-world observational constraint on how much the regional model can diverge from reality. This is not the case with type 4 downscaling. A type 4 downscaling cannot be more accurate than a type 2 downscaling.

A more appropriate approach is to first assess what changes in climate statistics would have to occur in order to cause a negative impact to key resources, as we recommend in Pielke et al. $(2012,2013)$. Only then can we assess what is plausibly possible and how to mitigate/ adapt to prevent a negative effect from occurring.

The type of downscaling used in a study is a critically important point that needs to be emphasized when dynamic downscaling studies are presented. Mearns et al. (2012) did not do this.

Indeed, Mearns et al. (2012) is a study of the current climate, not of changes in climate statistics over the time period of the model runs. The Mearns et al. (2012) study did not look at the issue of their skill to predict changes in climate statistics. Even reproducing the current regional climate in a hindcast mode when the results are not constrained by reanalyses is being shown to be a daunting challenge (Xu et al. 2012; Fyfe et al. 2011; van Oldenborgh et al. 2012; Anagnostopoulos et al. 2010; Stephens et al. 2010; Sun et al. 2012; van Haren et al. 2013; Kundzewicz et al. 2010; Goddard et al. 2013; Driscoll et al. 2012; Mauritsen et al. 2012; Jiang et al. 2012; Sakaguchi et al. 2012).

It is even more challenging to skillfully predict changes in regional climate, which is what is required if the RCMs are to add any value for predicting climate in the coming decades beyond what could be extracted from reanalyses. The impacts community should be aware that the Mearns et al. (2012) paper addresses type 2 dynamic downscaling only. Their results do not provide a measure of the skill of multidecadal regional climate change prediction (i.e. type 4 downscaling)
In summary, the Mearns et al. (2012) BAMS paper with respect to type 2 downscaling is an important new contribution. However, its application to climate change runs (type 4 downscaling) is inappropriate and misleading to the impacts and policy communities on a level of predictive skill that does not yet exist.

\section{REFERENCES}

Anagnostopoulos, G. G., D. Koutsoyiannis, A. Christofides, A. Efstratiadis, and N. Mamassis, 2010: A comparison of local and aggregated climate model outputs with observed data. Hydrol. Sci. J., 55, 1094-1110.

Castro, C. L., R. A. Pielke Sr., and G. Leoncini, 2005: Dynamical downscaling: Assessment of value retained and added using the Regional Atmospheric Modeling System (RAMS). J. Geophys. Res., 110, D05108, doi:10.1029/2004JD004721.

Driscoll, S., A. Bozzo, L. J. Gray, A. Robock, and G. Stenchikov, 2012: Coupled Model Intercomparison Project 5 (CMIP5) simulations of climate following volcanic eruptions. J. Geophys. Res., 117, D17105, doi:10.1029/2012JD017607.

Fyfe, J. C., W. J. Merryfield, V. Kharin, G. J. Boer, W.-S. Lee, and K. von Salzen, 2011: Skillful predictions of decadal trends in global mean surface temperature. Geophys. Res. Lett., 38, L22801, doi:10.1029/2011GL049508.

Goddard, L., and Coauthors, 2013: A verification framework for interannual-to-decadal predictions experiments. Climate Dyn., 40, 245-272, doi:10.1007/ s00382-012-1481-2.

Jiang, J. H., and Coauthors, 2012: Evaluation of cloud and water vapor simulations in CMIP5 climate models using NASA "A-Train" satellite observations. J. Geophys. Res., 117, D14105, doi:10.1029/2011JD017237.

Kundzewicz, Z. W., and E. Z. Stakhiv, 2010: Are climate models "ready for prime time" in water resources management applications, or is more research needed? Hydrol. Sci. J., 55, 1085-1089.

Mauritsen, T., and Coauthors, 2012: Tuning the climate of a global model. J. Adv. Model. Earth Syst., 4, M00A01, doi:10.1029/2012MS000154.

Mearns, L. O., and Coauthors, 2012: The North American Regional Climate Change Assessment Program: Overview of phase I results. Bull. Amer. Meteor. Soc., 93, 1337-1362.

Pielke, R. A., Sr., 2002: Overlooked issues in the U.S. national climate and IPCC assessments. Climate Change, 52, 1-11, doi:10.1023/A:1017473207687. 
Pielke, R. A., Sr., and R. L. Wilby, 2012: Regional climate downscaling: What's the point? Eos, Amer. Geophys. Union, 93, 52-53, doi:10.1029/2012EO050008.

_- and Coauthors, 2012: Dealing with complexity and extreme events using a bottom-up, resourcebased vulnerability perspective. Extreme Events and Natural Hazards: The Complexity Perspective. Geophys. Monogr., Vol. 196, Amer. Geophys. Union, 345-359.

—, and Coauthors, Eds., 2013: Introduction. Climate Vulnerability, Understanding and Addressing Threats to Essential Resources, 1st ed., Academic Press, 1-17.

Prudhomme, C., R. L. Wilby, S. Crooks, A. L. Kay, and N. S. Reynard, 2010: Scenario-neutral approach to climate change impact studies: Application to flood risk. J. Hydrol., 390, 198-209, doi:10.1016/j. jhydrol.2010.06.043.

Sakaguchi, K., X. Zeng, and M. A. Brunke, 2012: The hindcast skill of the CMIP ensembles for the surface air temperature trend. J. Geophys. Res., 117, D16113, doi:10.1029/2012JD017765.
Stephens, G. L., and Coauthors, 2010: Dreary state of precipitation in global models, J. Geophys. Res., 115, D24211, doi:10.1029/2010JD014532.

Sun, Z., J. Liu, X. Zeng, and H. Liang, 2012: Parameterization of instantaneous global horizontal irradiance: Cloudy-sky component. J. Geophys. Res., 117, D14202, doi:10.1029/2012JD017557.

van Haren, R., G. J. van Oldenborgh, G. Lenderink, M. Collins, and W. Hazeleger, 2013: SST and circulation trend biases cause an underestimation of European precipitation trends. Climate Dyn., 40, 1-20, doi:10.1007/s00382-012-1401-5.

van Oldenborgh, G. J., F. J. Doblas-Reyes, B. Wouters, and W. Hazeleger, 2012: Decadal prediction skill in a multi-model ensemble. Climate Dyn., 38, 1263-1280, doi:10.1007/s00382-012-1313-4.

Xu, Z., and Z.-L. Yang, 2012: An improved dynamical downscaling method with GCM bias corrections and its validation with 30 years of climate simulations. J. Climate, 25, 6271-6286, doi:10.1175/JCLID-12-00005.1. 